\title{
Pharmacology of the porcine ureter - the effect of age
}

\author{
Iris Lim, Russ Chess-Williams, Donna Sellers
}

\section{Centre for Urology Research, Bond University, Gold Coast, Australia}

Background: Ageing has been reported to increase the risk of ureteral calculus development. The cholinergic, $\alpha$ adrenergic, and 5-hydroxytryptamine (5-HT) systems have been shown to increase ureteric contraction and hence, have a significant role in ureteral obstruction. The aim of this study was to compare the effects of selective agonists at these receptors in ureteral tissues from young and older pigs.

Method: Contractile responses of isolated smooth muscle strips to phenylephrine ${ }_{s}$, carbachol and 5-HT were examined in distal ureteral tissues from young (20 weeks) and older (56 weeks) pigs. Tissues developed spontaneous contractile activity and responses were expressed as area under the curve (AUC) $\left(\mathrm{g}^{-1} \mathrm{~s}\right)$ and frequency (contractions/min) normalised to tissue weights.

Results: When subjected to increasing concentrations of phenylephrine and 5-HT, porcine ureteral tissues from both age groups developed bursts of phasic contractions, and increasing agonist concentrations caused increased frequency of phasic activity. In response to carbachol, this similar pattern of contractions was observed in tissues from the older animals, but tissues from the younger animals did not exhibit any response to carbachol. The potency (pEC50) values of other agonists were similar for tissues from both age groups (young vs older: $4.42 \pm 0.18$ vs $4.83 \pm 1.43$ for phenylephrine, $5.16 \pm 0.09$ vs $5.43 \pm 0.16$ for 5 -HT). However, the maximum contractile responses expressed as AUC to phenylephrine were significantly enhanced in tissues from the older group (Figure $1 \mathrm{~A}, \mathrm{p}<0.001$ ). Phenylephrine-induced frequency of contractions was also greater in older animals (young vs older: $8.88 \pm 0.91$ vs $12.9 \pm 1.2$ contractions/min respectively). Tissues from younger animals failed to respond to carbachol, but in older animals, ureteral strips developed contractile activity and the maximum frequency of contractions was $1.86 \pm 0.12$ contractions $/ \mathrm{min}$. In contrast, for 5 -HT, maximum AUC contractile responses were depressed in tissues from older animals (Figure 1B, $\mathrm{p}<0.001$ ). However, the maximum frequency response was similar in tissues from both age groups (young vs older, $11.58 \pm 0.54$ vs $12.72 \pm 0.84$ contractions/min).

Conclusion: These results suggest that there are age-related changes in the contractile responsiveness of the ureter which may alter the effectiveness of agents used to induce ureteral relaxation. 